BERTASO, João Martins; BERTASO, Candice Nunes. Aspectos da subjetividade na questão de gênero em Luis Alberto Warat. Revista Eletrônica Direito e Política, Programa de Pós-Graduação Stricto Sensu em Ciência Jurídica da UNIVALI, Itajaí, v.15, n.3, 3ㅇ quadrimestre de 2020 . Disponível em: www.univali.br/direitoepolitica - ISSN 1980-7791

\title{
ASPECTOS DA SUBJETIVIDADE NA QUESTÃO DE GÊNERO EM LUIS ALBERTO WARAT
}

\author{
ASPECTS OF SUBJECTIVITY IN THE GENDER ISSUE IN \\ LUIS ALBERTO WARAT
}

\author{
João Martins Bertaso ${ }^{1}$ \\ Candice Nunes Bertaso²
}

\section{RESUMO}

O ensaio pretende verificar a existência de um poder impessoal e simbolicamente instituído que disciplina a instituição da sociedade na determinação dos sujeitos sociais. O objetivo é verificar como o poder é inserido nas significações imaginárias das pessoas e o processo pelo qual, ambos os sexos estão recondicionando a forma de representação da sociedade, especificamente no que se refere aos seus papéis e espaços sociais. Assim, a questão do gênero é vinculada à construção da subjetividade e de que a ordem social natural totalitária produz uma subjetividade simbólica ilusória, mas determinante das relações sociais de poder e força. A categoria de gênero é colocada em discussão para demonstrar as implicações que o exercício do poder tem sobre a configuração da subjetividade masculina e feminina. O ensaio ancorou seu aporte teórico, sob o olhar do feminino, a partir de Luis Alberto Warat, além dos autores Alain Touraine, Gilles Lipovetky, Riane Eisler, Manuel Castells. Charles Taylor, Alex Honneth e Maria Rita Kehl.

\footnotetext{
${ }^{1}$ Pós-doutor pela UNISINOS. Doutor e mestre em Direito, pela Universidade Federal de Santa Catarina/UFSC. Especialista em Direito, pela Universidade Federal de Santa Maria/UFSM. Bacharel em Direito, pela Faculdade de Direito de Santo Ângelo/FADISA. Graduado em Pedagogia pela Faculdade de Filosofia Ciências e Letras de Santo Ângelo. Líder de grupo de pesquisa "Conflito, Cidadania e Direitos Humanos" no CNPq. Doutor Pesquisador vinculado a URI - Universidade Regional Integrada de Santo Ângelo-RS. Coordenador do Programa de Pós-Graduação em Direito - Mestrado e Doutorado da URI/Santo Ângelo-RS. Desenvolve pesquisa em cidadania, direitos humanos, interculturalidade e psicanálise. E-mail: joaomartinsbertaso@gmail.com

${ }^{1} \mathrm{O}$ presente trabalho é um quesito a ser cumprido para conclusão do Estágio Pós-Doutoral em Direito, que está sendo realizado junto ao PPG Direito da Universidade Regional Integrada do Alto Uruguai e das Missões - URI Campus de Santo Ângelo - RS, por Domingos Benedetti Rodrigues, sob a orientação do o Prof. Dr João Martins Bertaso.
}

2 Mestre e Doutoranda em Direito pela URI - Campus Santo Ângelo/RS. Bolsista CAPES/CNPQ. E-mail: candybertaso@yahoo.com.br 

Alberto Warat. Revista Eletrônica Direito e Política, Programa de Pós-Graduação Stricto Sensu em Ciência Jurídica da UNIVALI, Itajaí, v.15, n.3, 3ㅇ quadrimestre de 2020 . Disponível em: www.univali.br/direitoepolitica - ISSN 1980-7791

PALAVRAS-CHAVE: Subjetividade, Gênero, Feminino.

\section{ABSTRACT}

The essay aims to verify the existence of an impersonal and symbolically instituted power that disciplines the institution of society in determining social subjects. The objective is to verify how power is inserted in people's imaginary meanings and the process by which both sexes are reconditioning the form of representation of society, specifically with regard to their roles and social spaces. Thus, the issue of gender is linked to the construction of subjectivity and that the totalitarian natural social order produces an illusory symbolic subjectivity, but determinant of the social relations of power and strength. The gender category is put into discussion to demonstrate the implications that the exercise of power has on the configuration of male and female subjectivity. The essay anchored its theoretical contribution, under the eyes of the feminine, from Luis Alberto Warat, in addition to the authors Alain Touraine, Gilles Lipovetky, Riane Eisler, Manuel Castells. Charles Taylor, Alex Honneth and Maria Rita Kehl.

KEYWORDS: Subjectivity, Gender, Female.

\section{INTRODUÇÃO}

O presente trabalho pretende verificar como se produz a subjetividade no âmbito da sociedade, estabelecendo uma divisão social dos papéis atribuídos ao homem e à mulher. A temática desse ensaio teórico visa constatar a existência de um poder impessoal e simbolicamente instituído que disciplina a instituição da sociedade e determina o papel dos sujeitos sociais. Pretende-se verificar como esse poder repercute nas significações imaginárias das pessoas e o processo pelo qual, ambos os sexos estão recondicionando a forma de representação da sociedade, especificamente no que se refere aos seus papéis e espaços sociais.

O ensaio trabalha a ideia de que a questão do gênero é vinculada à construção da subjetividade e de que a ordem social natural totalitária produz uma subjetividade simbólica. A partir disso a categoria de gênero é colocada em 

Jurídica da UNIVALI, Itajaí, v.15, n.3, 3ㅇ quadrimestre de 2020 . Disponível em: www.univali.br/direitoepolitica - ISSN 1980-7791

discussão para demonstrar as implicações que o exercício do poder tem sobre a configuração da subjetividade masculina e feminina. O gênero determinando as áreas de poder diferenciadas para ambos os tipos de subjetividade, com distintos efeitos sociais.

Desse modo é que se pretende vincular a ideia de igualdade, diferença, reconhecimento, identidade e autonomia como condição de possibilidade de resgate da subjetividade masculina e feminina e a busca de sentido para suas próprias vidas se liberando das normas convertidas em modelo e condições para a dominação.

Importa a este trabalho demonstrar os processos de transformação e de convergência entre os papéis de gênero tradicionais e modernos na vida das pessoas, em especial das mulheres atuais, como também, o poder de autodeterminação e indeterminação subjetiva dos gêneros.

Assim, desde esta reflexão teórica, o tema escolhido centra-se em estabelecer uma construção espistemológica através do feminino, a partir de um referencial teórico Waratiano e dentre outros autores como Alain Touraine, Gilles Lipovetky, Riane Eisler, Manuel Castells e Maria Rita Kehl. É uma construção de uma racionalidade a partir do feminino, com várias possibilidades de decisão e de construção da vida e das realidades que permitem a liberdade de escolha, a autocriação e o processo de autodeterminação e indeterminação subjetiva dos gêneros, abrindo um caminho de fuga, um descolamento, uma ruptura com o discurso do poder masculino instituído e de seus efeitos imaginários estabelecidos por uma sociedade patriarcal sobre a determinação da subjetividade masculina ou feminina. 

Alberto Warat. Revista Eletrônica Direito e Política, Programa de Pós-Graduação Stricto Sensu em Ciência Jurídica da UNIVALI, Itajaí, v.15, n.3, 3ㅇ quadrimestre de 2020 . Disponível em: www.univali.br/direitoepolitica - ISSN 1980-7791

\section{A CATEGORIA dO GÊNERO E AS LUTAS POR RECONHECIMENTO.}

O movimento feminista contemporâneo teve seu início no século XIX e foi considerado o movimento social mais humanizador da modernidade. ${ }^{3} \mathrm{O}$ movimento feminista modificou de forma significativa a condição das mulheres em diversos países, porém não naqueles onde a dominação masculina ainda permanece.

Maria Berenice Dias constata que as mulheres têm lutado "arduamente na conquista de direitos iguais e para o filósofo Norberto Bobbio promoveram a maior revolução deste século". ${ }^{4} \mathrm{O}$ movimento feminista reivindica um espaço para as mulheres na sociedade em igualdade de condições com os homens, bem como dar fim às discriminações por elas sofridas, uma vez que foram submetidas a uma ordem dominante masculina por muito tempo.

$O$ intenso envolvimento das mulheres nas lutas por reconhecimento e em busca de igualdade aumentou a partir do século XX,

[...] o mundo nunca havia testemunhado crescimento tão rápido de organizações governamentais e não governamentais com milhões de associados todas dedicadas à melhoria das condições femininas. Nunca tinha havido uma Década das Nações Unidas para Mulheres. Nunca tinha havido conferências globais atraindo milhares de mulheres de todos os cantos do mundo para tratar dos problemas da supremacia masculina. Nunca, em toda a história registrada, as mulheres de todas as nações da Terra se haviam reunido para trabalhar em prol de um futuro de igualdade sexual, desenvolvimento e paz - os três objetivos da Primeira Década das Nações Unidas para as Mulheres. ${ }^{5}$

3 EISLER, Riane. O cálice e a espada - Nossa história, nosso futuro. Rio de Janeiro: Imago Ed, 1989.

${ }^{4}$ DIAS, Maria Berenice. Aspectos jurídicos do gênero feminino. Construções e perspectivas em gênero. Organizado por Marlene Neves Strey; Flora Mattos; Gilda Fensterseifer e Graziela Werba. São Leopoldo: Ed. UNISINOS, 2000.

5 EISLER, Riane. O cálice e a espada - Nossa história, nosso futuro. Rio de Janeiro: Imago Ed, 1989, p. 195. 
BERTASO, João Martins; BERTASO, Candice Nunes. Aspectos da subjetividade na questão de gênero em Luis Alberto Warat. Revista Eletrônica Direito e Política, Programa de Pós-Graduação Stricto Sensu em Ciência Jurídica da UNIVALI, Itajaí, v.15, n.3, 3ㅇ quadrimestre de 2020 . Disponível em: www.univali.br/direitoepolitica - ISSN 1980-7791

As demandas continuam sendo produzidas no centro de mobilizações, entretanto, elas deixam de apresentar interesses universais de categorias, como fizera o movimento operário, e passam a buscar o respeito as suas particularidades culturais. ${ }^{6} \mathrm{O}$ autor afirma que os movimentos sociais buscam a identidade que querem preservar ou construir, um espaço na sociedade ou de fundamentos próprios de orientação para suas demandas. Unem-se a um objetivo comum, como por exemplo, a resistência a uma regra, ou a uma luta contra algum constrangimento social, cultural, político ou econômico, como também a uma pertença herdada, como cor, etnia, sexo, entre outros. ${ }^{7}$

Quanto ao reconhecimento dos movimentos sociais e identitário, Touraine constata que os novos movimentos sociais defendem a liberdade e a responsabilidade de cada indivíduo que pode ser tanto sozinho ou em coletividade. Essa defesa se faz "contra uma ordem estabelecida que decide o que é normal ou anormal, permitido ou proibido". 8 Conforme o autor, a concepção de "reconhecimento" como condição de realização de si mesmo, proposta por Charles Taylor, trata de que

[...] o objetivo principal do movimento social é a realização de si mesmo como ator, capaz de transformar sua situação e seu ambiente, ou seja, de ser reconhecido como sujeito, cada vez que o ator reconhece que sua capacidade de ser um ator livre, e não o produto de construções sociais que ele não domina, depende da solução de um conflito em que ele está engajado. ${ }^{9}$

\footnotetext{
6 TOURAINE, Alain. Um novo paradigma: para compreender o mundo de hoje / Alain Touraine; tradução de Gentil Avelino Titton. Petrópolis, RJ: Vozes, 2006.

7 Alain Touraine explica que os sujeitos, em suas reivindicações, buscam redefinir relações, a partir dos indivíduos "que sofrem experiências que negam suas identidades, sofrem opressões ou estão excluídos ou discriminados, ou resistem às regras que são impostas (novas políticas para imigrantes, por exemplo)" (GOHN, 2010, p. 121).

8 TOURAINE, Alain. Um novo paradigma: para compreender o mundo de hoje / Alain Touraine; tradução de Gentil Avelino Titton. Petrópolis, RJ: Vozes, 2006, p. 180.

9 TAYLOR, Charles. El multiculturalismo y "la política del reconocimiento". Tradução Mónica Utrilla de Neira. México: Fondo de Cultura Ecónomica, 2006. p. 176.
} 
BERTASO, João Martins; BERTASO, Candice Nunes. Aspectos da subjetividade na questão de gênero em Luis Alberto Warat. Revista Eletrônica Direito e Política, Programa de Pós-Graduação Stricto Sensu em Ciência Jurídica da UNIVALI, Itajaí, v.15, n.3, 3ㅇ quadrimestre de 2020 . Disponível em: www.univali.br/direitoepolitica - ISSN 1980-7791

As demandas pelo reconhecimento das diferenças necessitam ser atendidas, e, nesse sentido, Axel Honneth traz uma nova visão ancorada no processo de construção social da identidade e que passa a ter como gramática, a luta pela construção da identidade entendida como uma luta pelo reconhecimento.

Para Sergio Costa "as lutas efetivas por reconhecimento pessoal ou coletivo devem construir o terreno social para a sustentação de uma teoria crítica da sociedade". ${ }^{10}$ Nessa esteira, Marcos Nobre alega que

As lutas sociais que Honneth privilegia em sua teoria do reconhecimento são decorrentes dos 'conflitos que se originam de uma experiência de desrespeito social, de um ataque à identidade pessoal ou coletiva, capaz de suscitar uma ação que busque restaurar relações de reconhecimento mútuo ou justamente desenvolvê-la num nível evolutivo superior'. Por isso, para Honneth, é possível ver nas diversas lutas por reconhecimento uma força moral que impulsiona movimentos sociais. ${ }^{11}$

Touraine identifica uma nova realidade quando se refere às mudanças de paradigma que a sociedade vem sofrendo, constatando que as mulheres serão as atrizes principais desta ação, já que foram consideradas como categoria inferior por meio da dominação masculina. Afirma o autor, que "o que estamos vivendo é a inversão do modelo clássico da modernidade, tão fortemente polarizado. As categorias dominadas - o povo, os trabalhadores, os colonizados, as mulheres - transformaram-se em movimentos sociais, que cortaram o laço de dependência que fazia delas escravos de um senhor". ${ }^{12}$

\footnotetext{
10 COSTA, Sérgio. Complexidade, diversidade e democracia. In Souza, Jessé (org). Democracia hoje: novos desafios para a teoria democrática contemporânea. Brasília: editora Universidade de Brasília, 2001 , p. 472.

11 NOBRE, Marcos. Luta por reconhecimento: Axel Honneth e a teoria crítica. In: HONNETH, Axel. Luta por reconhecimento: a gramática moral 'dos conflitos sociais. São Paulo: Ed. 34, 2003, p. 18.

1212 TOURAINE, Alain. Um novo paradigma: para compreender o mundo de hoje / Alain Touraine; tradução de Gentil Avelino Titton. Petrópolis, RJ: Vozes, 2006, p. 213. O objetivo hoje é reunir o que foi separado pela primeira modernização, o de uma extrema polarização entre homens e mulheres que suscitou tensões e conflitos extremos. O único movimento cultural capaz de propor em nossa sociedade uma nova criatividade é o que procura recompor a vida social e a experiência pessoal.
} 
BERTASO, João Martins; BERTASO, Candice Nunes. Aspectos da subjetividade na questão de gênero em Luis Alberto Warat. Revista Eletrônica Direito e Política, Programa de Pós-Graduação Stricto Sensu em Ciência Jurídica da UNIVALI, Itajaí, v.15, n.3, 3ㅇ quadrimestre de 2020 . Disponível em: www.univali.br/direitoepolitica - ISSN 1980-7791

Segue Touraine: "as lutas em que as mulheres desempenham um papel central não visam substituir a dominação masculina por uma dominação feminina", 13 não diz respeito a uma superação das mulheres em relação aos homens, visam somente à igualdade, reconhecimento e aceitação, mas respeitando as diferenças. Nesse mesmo sentido, Touraine explica que

[...] é por esse motivo que nos movimentos femininos encontram-se reivindicações que vão além dos direitos políticos ou da igualdade econômica. Lutam por sua liberdade, ou seja, aspiram se libertar da imagem da mulher produzida pela cultura de massa, que a seu ver, as 'alienam' e negam suas condutas reais e suas iniciativas. Da mesma forma, os imigrantes não protestam apenas contra a exploração econômica ou contra arbitrariedade policial. Referente às minorias sexuais, a luta que estas travam se direciona contra as imagens da 'moralidade' que as confinam na marginalidade e num status inferior. Nesse caso, também se está diante de um movimento de libertação que tem como objetivo a eliminação de todas as formas de interdito e discriminação. Os movimentos sociais se definem sobretudo, por uma relação dos indivíduos em questão com eles mesmos. ${ }^{14}$

Já Taylor alerta que o igual reconhecimento não é somente uma qualidade de uma sociedade democrática saudável, mas que também, a sua negação pode causar consequências negativas aos sujeitos em relação à sua identidade, explicando que

A exigência de reconhecimento assume nesses casos caráter de urgência dados os supostos vínculos entre reconhecimento e identidade, em que "identidade" designa algo como uma compreensão de quem somos, de nossas características definitórias fundamentais como seres humanos. A tese é de que nossa identidade é moldada em parte pelo reconhecimento ou por sua ausência, frequentemente pelo reconhecimento errôneo por parte dos outros, de modo que uma pessoa ou grupo de pessoas pode

1313 TOURAINE, Alain. Um novo paradigma: para compreender o mundo de hoje / Alain Touraine; tradução de Gentil Avelino Titton. Petrópolis, RJ: Vozes, 2006, p. 228.

1414 TOURAINE, Alain. Um novo paradigma: para compreender o mundo de hoje / Alain Touraine; tradução de Gentil Avelino Titton. Petrópolis, RJ: Vozes, 2006, p. 172. 
BERTASO, João Martins; BERTASO, Candice Nunes. Aspectos da subjetividade na questão de gênero em Luis Alberto Warat. Revista Eletrônica Direito e Política, Programa de Pós-Graduação Stricto Sensu em Ciência Jurídica da UNIVALI, Itajaí, v.15, n.3, 3ㅇ quadrimestre de 2020 . Disponível em: www.univali.br/direitoepolitica - ISSN 1980-7791

sofrer reais danos, uma real distorção, se as pessoas ou sociedades ao redor deles Ihes devolverem um quadro de si mesmas redutor, desmerecedor ou desprezível. O nãoreconhecimento ou o reconhecimento errôneo podem causar danos, podem ser uma forma de opressão, aprisionando alguém numa modalidade de ser falsa, distorcida e redutora. 15

Outro aspecto importante é o que diz respeito ao contexto político onde ocorrem as lutas por reconhecimento. As lutas de gênero, a convivência de padrões muito tradicionais entre homens e mulheres com um movimento feminista e difuso, mas culturalmente influente, impôs a concepção de instrumentos de combate ao sexismo e à singularidade sociocultural do país. Importa ainda mencionar que essas lutas por reconhecimento expressam o seu caráter político, pois elas não podem restringir-se tão somente à esfera da cultura, "é preciso que haja possibilidades políticas de tratamento dessas demandas e a abertura para a crítica às instituições políticas e mecanismos econômicos que reproduzem a inequidade racial ou de gênero". ${ }^{16}$

Nancy Fraser utiliza-se da Teoria da Redistribuição para explicar como a má distribuição econômica, de direitos, entre outros, gerado pelo sistema capitalista, atravancam a ascensão social das mulheres, principalmente aquelas mais afetadas pela desigualdade social, impedindo assim, a sua emancipação. Nesse contexto, Fraser discute a problemática da injustiça de gênero através de três dimensões de justiça, que são: redistribuição, reconhecimento e representação. Como também, a importância dos movimentos sociais, como o feminista, para a materialização da justiça de gênero. ${ }^{17}$

\footnotetext{
15 TAYLOR, Charles. Argumentos Filosóficos. São Paulo: Edições Loyola, 2000. p. 241.

16 COSTA, Sérgio. Complexidade, diversidade e democracia. In Souza, Jessé (org). Democracia hoje: novos desafios para a teoria democrática contemporânea. Brasília: editora Universidade de Brasília, 2001, p. 473.

17 FRASER, Nancy. Redistribuição, reconhecimento e diferença: por uma concepção integrada de justiça. In: IKAWA, Daniela; PIOVESAN, Flávia, SARMENTO, Daniel (org.). Igualdade, diferença e direitos humanos. Rio de Janeiro: Lumen Juris, 2008. p. 14-29.
} 

Jurídica da UNIVALI, Itajaí, v.15, n.3, 3ㅇ quadrimestre de 2020 . Disponível em: www.univali.br/direitoepolitica - ISSN 1980-7791

As organizações de base popular, criadas e dirigidas por mulheres, transformaram a condição, organização e conscientização destas. Por esse olhar, Manuel Castells sinaliza que "esses esforços coletivos não resultaram apenas de organizações populares, causando impacto nas políticas e instituições, mas também no surgimento de uma nova identidade coletiva, na forma de mulheres capacitadas" 18 .

Não se tem uma precisão de quando se estabeleceu a marginalização das mulheres no contexto histórico da humanidade. O que se pode afirmar é que as discriminações entre homens e mulheres acompanharam grande parte da história da civilização. Entretanto, os movimentos de mulheres criaram todas as condições para a reconstrução da subjetividade, tanto individual quanto coletiva. Com a intensificação desses movimentos, que se deu após a Revolução Francesa, desencadeou-se uma marcante quebra de paradigmas, surgindo assim, uma nova história das mulheres.

Para Riane Eisler, as ideologias progressistas da modernidade podem ser vistas como parte de uma revolução crescente contra a androcracia, ou seja, contra o sistema de depreciação da mulher e do feminino, com a supremacia do homem sobre a mulher. De todas as ideologias progressistas, só o feminismo busca igualdade e liberdade para toda a humanidade (não somente para uma metade da humanidade), [...]. 19

Para Michelle Perrot,

defender os direitos das mulheres não significa que as mulheres tenham todos os direitos. Havia uma razão para lutar pelo direito das mulheres: a desigualdade era $\mathrm{e}$ continua sendo muito flagrante. Mas se as mulheres se tornam mais fortes, têm também contas a prestar: elas não têm necessariamente razão, nem todos os direitos, diante

18 CASTELLS, Manuel. O Poder da Identidade. A Era da Informação: Economia, Sociedade e Cultura. Vol.

2. São Paulo: Editora Paz e Terra, 1999. p. 222.

19 EISLER, Riane. O cálice e a espada - Nossa história, nosso futuro. Rio de Janeiro: Imago Ed, $1989, \mathrm{p}$. 214-216. 

Jurídica da UNIVALI, Itajaí, v.15, n.3, 3ㅇ quadrimestre de 2020 . Disponível em: www.univali.br/direitoepolitica - ISSN 1980-7791

das crianças ou dos homens. O mundo atual tenta pensar as liberdades de cada um ao máximo, recompor os códigos e equilibrar as liberdades. 20

Com o olhar na história humana, Eisler menciona que após cerca de cinco mil anos de vida em uma sociedade dominadora, parece ser difícil um mundo diferente. Mas hoje, homens e mulheres de todo o mundo estão desafiando o modelo masculino e dominador com o feminino e dominado para as relações humanas. Tanto para homens quanto para mulheres, esta supremacia de uma metade da humanidade sobre a outra, envenena todas as relações humanas. ${ }^{21}$

\section{JÁ TEMOS UM PONTO DE PARTIDA}

Pretende-se que homens e mulheres tenham igualdade de condições em todas as esferas da vida pública e privada, para que vivam em harmonia em busca de uma sociedade mais justa e de vida digna a todos os cidadãos. Todavia, mesmo diante desta reviravolta das mulheres, se sabe que elas ainda não atingiram essa tão desejada igualdade, uma vez que grande parcela de mulheres ainda convive com diversas formas de discriminação, sujeitando-se assim, a tratamentos indignos que não condizem com o previsto no ordenamento jurídico brasileiro.

Quando homens e mulheres viverem em uma sociedade mais equilibrada e igualitária, e ambos os sexos viverem em integral parceria, a sociedade como um todo ganhará mais qualidade de vida, pois os papéis de homens e mulheres serão bem menos rígidos, possibilitando a toda espécie humana o máximo de flexibilidade evolutiva. E terminarão por descobrir o que pode literalmente significar "ser humano".

Práticas tais como mutilação sexual feminina, o espancamento de esposas ou as formas menos brutais,

\footnotetext{
20 PERROT, Michelle. Mulheres públicas. São Paulo: Fundação Editora da UNESP, 1998. p. 143.

${ }^{21}$ EISLER, Riane. O cálice e a espada - Nossa história, nosso futuro. Rio de Janeiro: Imago Ed, 1989.
} 
BERTASO, João Martins; BERTASO, Candice Nunes. Aspectos da subjetividade na questão de gênero em Luis Alberto Warat. Revista Eletrônica Direito e Política, Programa de Pós-Graduação Stricto Sensu em Ciência Jurídica da UNIVALI, Itajaí, v.15, n.3, 3ㅇ quadrimestre de 2020 . Disponível em: www.univali.br/direitoepolitica - ISSN 1980-7791

através das quais a androcracia vem mantendo as mulheres 'no seu devido lugar', naturalmente serão consideradas não como tradições consagradas mas como o que de fato são crimes gerados pela desumanidade do homem para com a mulher. 22

De acordo com Taylor, algumas mulheres internalizaram uma imagem de sua própria inferioridade, de modo que, mesmo quando se retiram os obstáculos para o seu avanço, podem ser incapazes de aproveitar as novas oportunidades, uma vez que estão condenadas a uma baixíssima autoestima. E complementa assegurando que "El reconocimiento devido no sólo es uma cortesía que debemos a los demás: es uma necesidad humana vital". ${ }^{23}$

As feministas, minorias em sociedades multiculturais, os povos que anseiam por independência nacional ou regiões colonizadas no passado e que hoje reclamam igualdade no cenário internacional, todos esses agentes sociais hoje lutam em favor de reivindicações de reconhecimento para identidades coletivas ou igualdade de direitos para formas de vida culturais. ${ }^{24}$

Quando se aborda essa questão, parece estar se tratando de temas diferentes, porém, ambos se unem para lutar por um mesmo ideal: luta por reconhecimento no meio social, cultural, político, familiar e público. ${ }^{25}$ Nas palavras de Jurgen Habermas, são fenômenos correspondentes. Assim,

Seu parentesco consiste em que as mulheres, as minorias étnicas e culturais, as nações e culturas todas se defendem da opressão, marginalização e desprezo, lutando, assim, pelo reconhecimento de identidades coletivas, seja no contexto de uma cultura majoritária, seja em meio à

\footnotetext{
22 EISLER, Riane. O cálice e a espada - Nossa história, nosso futuro. Rio de Janeiro: Imago Ed, 1989, EISLER, Riane. O cálice e a espada - Nossa história, nosso futuro. Rio de Janeiro: Imago Ed, 1989, p. 252.

23 TAYLOR, Charles. El multiculturalismo y "la política del reconocimiento". Tradução Mónica Utrilla de Neira. México: Fondo de Cultura Ecónomica, 2006, p. 45.

24 HABERMAS, Jurgen. A inclusão do outro. São Paulo: Loyola, 2002.

25 De todas as lutas por reconhecimento operadas pelos segmentos culturais minoritários, as que interessam para este artigo são as lutas das mulheres, portanto, é nestas que vai se basear. As mulheres não constituem minoria numérica, mas sim em representatividade nos poderes instituídos, onde o reconhecimento e a igualdade em relação aos homens não se dão de forma igualitária.
} 
BERTASO, João Martins; BERTASO, Candice Nunes. Aspectos da subjetividade na questão de gênero em Luis Alberto Warat. Revista Eletrônica Direito e Política, Programa de Pós-Graduação Stricto Sensu em Ciência Jurídica da UNIVALI, Itajaí, v.15, n.3, 3ㅇ quadrimestre de 2020 . Disponível em: www.univali.br/direitoepolitica - ISSN 1980-7791

comunidade dos povos. São todos eles movimentos de emancipação cujos objetivos políticos coletivos se definem culturalmente, em primeira linha, ainda que as dependências políticas e desigualdades sociais e econômicas também estejam sempre em jogo (...). Embora o feminismo não seja causa de uma minoria, ele se volta contra uma cultura dominante que interpreta a relação dos gêneros de uma maneira assimétrica e desfavorável à igualdade de direitos. A diferenciação de situações de vida e experiências peculiares ao gênero não recebe consideração adequada nem jurídica nem informalmente; tanto a autocompreensão cultural das mulheres quanto a contribuição que elas deram a cultura comum estão igualmente distantes de contar com o devido reconhecimento e com as definições vigentes, as carências femininas mal podem ser articuladas de forma satisfatória. Assim, a luta política por reconhecimento tem início com a luta pela interpretação de interesses e realizações peculiares aos diferentes gêneros; à medida que logra êxito, essa luta modifica a identidade coletiva das mulheres, e com ela a relação entre os gêneros, afetando assim, de forma imediata, a autocompreensão dos homens. 26

Em Luis Alberto Warat, a condição de marginalidade da mulher começou a se revelar de um modo diferente, entre as décadas de 1960 e 1970 e os estudos de gênero ${ }^{27}$ passaram a ganhar corpo.

Assim, foram abandonados alguns dos antigos confrontamentos entre os sexos e se passou a pôr ênfase nas consequências e significados que tem, para uma dada sociedade, pertencer a cada um dos sexos, devido ao fato de que os efeitos sociais desta pertinência, longe de serem naturais, são fruto do imaginário social instituído. São expressões de gênero: os sentidos socialmente atribuídos ao fato de ser homem ou mulher numa determinada formação social. A feminilidade ou masculinidade como um elaborado social que fixa posições hierárquicas e lugar de poder.

\footnotetext{
26 HABERMAS, Jurgen. A inclusão do outro. São Paulo: Loyola, 2002, p. 238.

27 WARAT, Luis Alberto. Por quem cantam as sereias / Luiz Alberto Warat; trad. Por Julieta Rodrigues Sabóia Cordeiro. Porto Alegre: Síntese, 2000. Quando se fala de gênero, para Warat, está se colocando a questão em discussão e as implicações que o exercício do poder tem sobre a configuração da subjetividade masculina e feminina. O gênero determinando as áreas de poder diferenciadas para ambos os tipos de subjetividade, com distintos efeitos sociais. Para o homem o poder econômico-racional. Para as mulheres o poder dos afetos.
} 
BERTASO, João Martins; BERTASO, Candice Nunes. Aspectos da subjetividade na questão de gênero em Luis Alberto Warat. Revista Eletrônica Direito e Política, Programa de Pós-Graduação Stricto Sensu em Ciência Jurídica da UNIVALI, Itajaí, v.15, n.3, 3ㅇ quadrimestre de 2020 . Disponível em: www.univali.br/direitoepolitica - ISSN 1980-7791

Desigualdades e discriminações. Estamos vendo a questão do gênero como um dos fatores da subjetividade masculinofeminina. Mas não é o único; deseja-se apontar um olhar diferente - ao lado de fatores religiosos, de classe, de raça, de formação educacional - sobre os devires da subjetividade humana. Falo dos efeitos imaginários da configuração de uma sociedade patriarcal sobre a determinação da subjetividade masculina ou feminina. ${ }^{28}$

Warat consegue expressar com precisão a situação de homens e mulheres nos espaços público e privado, ao declarar:

O homem, na liderança política, constituindo o mundo. A mulher na liderança emocional, dentro do âmbito doméstico, com o controle dos afetos que circulam na família. A mulher como elemento de contenção dos homens confrontados com as hostilidades da vida pública. A luta para o homem e o amoroso para a mulher. ${ }^{29}$

Há muito tempo, um princípio universal constitui as coletividades humanas estabelecendo uma divisão social dos papéis atribuídos ao homem e à mulher. Em outras palavras, é o domínio do homem sobre a mulher. Warat constata "a existência de um poder impessoal e anônimo que disciplina a instituição da sociedade e fabrica os sujeitos sociais". ${ }^{30}$ Ele fala de um poder "heterônomo, universal e unívoco", vinculado à linguagem e instituído socialmente. ${ }^{31}$

Como esse poder é inserido nas significações imaginárias das pessoas, ele se torna uma "força alienante da significação que impede a relação de pensamento com o desejo e o gosto de significar". 32 Tornamos-nos servos dessa voz alienante que se fixa na produção simbólica da subjetividade e da

\footnotetext{
28 WARAT, Luis Alberto. Por quem cantam as sereias / Luiz Alberto Warat; trad. Por Julieta Rodrigues Sabóia Cordeiro. Porto Alegre: Síntese, 2000, p. 133.

29 WARAT, Luis Alberto. Por quem cantam as sereias / Luiz Alberto Warat; trad. Por Julieta Rodrigues Sabóia Cordeiro. Porto Alegre: Síntese, 2000, p. 133.

30 WARAT, Luis Alberto. Manifestos para uma ecologia do desejo. São Paulo: Editora Acadêmica. 1990, p. 79.

31 WARAT, Luis Alberto. Manifestos para uma ecologia do desejo. São Paulo: Editora Acadêmica. 1990, p. 79.

32 WARAT, Luis Alberto. Manifestos para uma ecologia do desejo. São Paulo: Editora Acadêmica. 1990, p.79.
} 

Jurídica da UNIVALI, Itajaí, v.15, n.3, 3ㅇ quadrimestre de 2020 . Disponível em: www.univali.br/direitoepolitica - ISSN 1980-7791

realidade. As atividades de significar, segundo Warat, estão a serviço de um poder que se introduz coercitivamente e nos condena a pensar e sentir de acordo com elas.

O poder, segundo o autor, produz a realidade e a verdade, pressupondo um dispositivo repressor e como tal, produtor da realidade. Em sua obra A Ciência Jurídica e seus dois maridos, Warat fala

[...] todas as verdades, deveres, ritos, ideias e sentimentos congelados que não permitiram ao homem realizar sua autonomia, fizeram-no prisioneiro. Converteram-no em um ser miserável, roubando-lhe a alegria, a ingenuidade primordial e suas possibilidades de amor. 33

Quando Warat fala do "poder do significado, está pensando no controle do desejo pelo discurso", tornando as pessoas sem autonomia e negando a elas o desejo de uma vida boa. Quando o autor fala de um "desejo semioticamente erotizado", refere-se a um desejo que é construído segundo o modelo institucional. 34

Warat coloca que a concepção da modernidade e a da razão são masculinas. Diz que se acabou com o lado feminino do desejo que tem dois componentes articulados, quais sejam: a) a energia do masculino, da estabilidade, da defesa, do eterno, da proteção, do permanente; e, b) o lado feminino, do incerto, do novo, do indefinido, do indeterminado. O feminino manifesta-se como despertar das diferenças, para produzi-las com o outro. $O$ feminino resolve no incessante do novo, a criação do novo possível. Contudo, a modernidade, em nome da razão, afastou o feminino.

Uma construção epistemológica a partir do feminino alega Warat, trata-se "de uma busca de sentido (que se dá o nome de verdades) que ajude a pensar

\footnotetext{
33 WARAT Luis Alberto. A Ciência Jurídica e seus dos maridos. 2. Ed. Santa Cruz do Sul : EDUNISC, 2000, p. 16.

34 O sentido de desejo para Warat é o mesmo de Guatarri: "todas as formas de vontade de viver, amar, criar e de inventar uma outra sociedade, uma outra percepção do mundo e seus valores".
} 
BERTASO, João Martins; BERTASO, Candice Nunes. Aspectos da subjetividade na questão de gênero em Luis Alberto Warat. Revista Eletrônica Direito e Política, Programa de Pós-Graduação Stricto Sensu em Ciência Jurídica da UNIVALI, Itajaí, v.15, n.3, 3ㅇ quadrimestre de 2020 . Disponível em: www.univali.br/direitoepolitica - ISSN 1980-7791

uma realidade conflitiva, sem as remissões masculinas a uma essência última". É uma "construção de uma racionalidade a partir do feminino, não homogênea, [...] protagonista, com uma variada gama de possibilidades de decisão e de construção da vida e das realidades que limitam os desejos". ${ }^{35}$

Sabe-se que é através da linguagem que o poder aparece como uma relação de força e ingere-se sobre os corpos produzindo a realidade e a verdade. Dessa forma, a ordem social natural, através de tal linguagem totalitária produz uma subjetividade simbólica ilusória. Warat relata que a "questão do gênero é vinculada à construção da subjetividade. A construção da subjetividade normatizada posta em crise, a partir da subjetividade feminina, para os dois sexos". 36

Warat também nos faz indagar sobre o poder da castração, que considera como a cultura do imobilismo da sociedade. É a totalitária imposição de uma unidade, o distanciamento de nossos desejos, a impossibilidade de conhecerse a si mesmo e o terror frente ao plural. Ensina que o Ocidente estabeleceu a ciência como castração Nos distanciou de toda ciência da transformação, "da produção do novo em mim e no outro" $37 \mathrm{E}$ explica que

A castração vista como uma rede de condenações: o sexo/ o amor/ o corpo/... e tudo o que permite ao homem encontrar os apoios para alcançar sua autonomia. A castração tem a ver com todas as barreiras, as cargas que nos impedem de conhecermo-nos, amarmo-nos, sentirmo-nos a nós mesmos. Tudo o que nos impossibilita para dar e receber amor. As peles invisíveis que nos distanciam do próprio corpo e do corpo dos outros. 38

\footnotetext{
35 WARAT, Luis Alberto. Territórios Desconhecidos: A Procura Surrealista pelos Lugares do Abandono do Sentido e da Reconstrução da Subjetividade. Vol 1. Florianópolis: Fundação Boiteux, 2004. p. 481.

36 WARAT, Luis Alberto. Territórios Desconhecidos: A Procura Surrealista pelos Lugares do Abandono do Sentido e da Reconstrução da Subjetividade. Vol 1. Florianópolis: Fundação Boiteux, 2004, p. 478.

37 WARAT, Luis Alberto. A Ciência Jurídica e seus dos maridos. 2. Ed. Santa Cruz do Sul : EDUNISC, 2000 , p. 18

38 WARAT, Luis Alberto. A Ciência Jurídica e seus dos maridos. 2. Ed. Santa Cruz do Sul : EDUNISC, 2000, p.16-17.
} 
BERTASO, João Martins; BERTASO, Candice Nunes. Aspectos da subjetividade na questão de gênero em Luis Alberto Warat. Revista Eletrônica Direito e Política, Programa de Pós-Graduação Stricto Sensu em Ciência Jurídica da UNIVALI, Itajaí, v.15, n.3, 3ㅇ quadrimestre de 2020 . Disponível em: www.univali.br/direitoepolitica - ISSN 1980-7791

Ainda no tocante à dominação, Michel Foucault, para quem a história da sexualidade pode ser entendida como uma história dos discursos sobre a sexualidade, afirma que

[...] a função das configurações familiares que se produziram na Europa a partir do século XVIII foi a de fixar dois dispositivos de controle: os de aliança (resumidamente: jurídico-institucionais), vigentes até então, aos novos dispositivos de sexualidade (psicossexuais). Os dispositivos psicossexuais atuam sobre cada sujeito e são passíveis de interpretações individuais. Em função dessa plasticidade, funcionam melhor em uma sociedade que passou rapidamente do monopólio de um discurso único (enunciado pelos representantes da Igreja Católica até pelo menos o final do século XVI) para a convivência com uma multiplicidade de enunciados organizadores da subjetividade. 39

Em substituição ao 'discurso unitário' (moral) da Idade Média, Foucault aponta que nos séculos seguintes 'esta relativa unidade foi decomposta, dispersada, reduzida a uma explosão de discursividades distintas que tomaram forma na demografia, na biologia, na medicina, na psiquiatria, na psicologia, na moral, na crítica política'. 40

Corroborando com a temática, Warat destaca o pensamento de Simone de Beauvior, que diz que a representação do mundo, assim como o mundo, é tarefa dos homens; eles os descrevem a partir de seu ponto de vista particular, que confundem com a verdade absoluta. ${ }^{41}$ No entanto, a fuga das formas simbólicas de poder do discurso, é uma forma de romper com a racionalidade positivista, isto é, uma ruptura simbólica do instituído. Assim, o autor sugere mudanças na forma de representação da sociedade, ou seja, transformações significativas nos modos da comunicação simbólica. Grande

\footnotetext{
39 FOUCAULT, Michel. A história da sexualidade. Rio de Janeiro: Graal, 1988, p. 35.

40 FOUCAULT, Michel. A história da sexualidade. Rio de Janeiro: Graal, 1988, p. 35.

41 WARAT, Luis Alberto. Territórios Desconhecidos: A Procura Surrealista pelos Lugares do Abandono do Sentido e da Reconstrução da Subjetividade. Vol 1. Florianópolis: Fundação Boiteux, 2004, p. 479.
} 

Jurídica da UNIVALI, Itajaí, v.15, n.3, 3ㅇ quadrimestre de 2020 . Disponível em: www.univali.br/direitoepolitica - ISSN 1980-7791

parte das lutas pela autonomia, diz o autor, são lutas de resistência e de descolamento do poder das significações. ${ }^{42}$

No tocante à resistência aos padrões sociais e às lutas por autonomia, Warat faz disso, uma "prática de uma semiologia do desejo: a aprendizagem do caráter inacabado das fantasias e do gozo que nos arrebata e sacode diante de um plural imperfeito de sentidos". Na semiologia do desejo "a linguagem descansa dos conceitos garantidos e toma fôlego para procurar a autonomia significativa e transgredir os sentidos petrificados do imaginário social". ${ }^{43}$ Situa-os à margem do poder e de suas determinações habituais.

Para Warat, a concepção da democracia, como uma ordem simbólica, encontra-se comprometida com o processo de reencontro do pensamento com o desejo e o gozo de significar. Segundo ele, a forma de revolução da sociedade deve ser transgressora, ou seja, é preciso transgredir a linguagem. Transgredir é transcender, é uma passagem que traz um conhecimento novo superando o passado. Assim, o autor explica que

A prática transgressora da linguagem encontra na perturbação erótica dos sentidos, uma possibilidade de fuga da alienação: a multivocidade dos sentidos transgredindo a verdade abusiva de todas as posturas unívocas e as mitologias totalizantes. ${ }^{4}$

Há uma inegável demanda social de uma política de atenção à particularidade, exigindo dessa forma uma redefinição da democracia. Pierre Rosanvallon traz a noção de care, que pode ser traduzida com, ocupar-se com o outro ou preocupar-se com os demais. O autor alega que

[...] el care lleva a destacar que no basta um principio de justicia para fundar una sociedade humana. En efecto, es

\footnotetext{
42 WARAT, Luis Alberto. Manifestos para uma ecologia do desejo. São Paulo: Editora Acadêmica. 1990.

43 WARAT, Luis Alberto. Manifestos para uma ecologia do desejo. São Paulo: Editora Acadêmica. 1990, p. 80.

44 WARAT, Luis Alberto. Manifestos para uma ecologia do desejo. São Paulo: Editora Acadêmica. 1990, p. 83-84.
} 

Jurídica da UNIVALI, Itajaí, v.15, n.3, 3ㅇ quadrimestre de 2020 . Disponível em: www.univali.br/direitoepolitica - ISSN 1980-7791

decisivo que, simultáneamente, sea honrado un tipo de relaciones sociales que valore, singularizándolos, a los individuos, que los constituya en sujetos importantes para los demás, que de alguna manera cuenten en el grupo, que sean dignos de atención. 45

No campo da democracia, a diversidade das situações e sua complexidade devem ser observadas e atendidas. Trata-se de uma generalidade desapegada das regras e das instituições. Tem sua origem no reconhecimento e possui um elemento de originalidade que não se pode deixar de levar em conta. Assim, a generalidade é um comportamento que considera com maior atenção o infinito mundo das singularidades. 46

Do ponto de vista de Maria Rita Kehl, "o ideal de autonomia, um dos valores constitutivos da cultura ocidental [...], funda-se numa autonomia subjetiva (imaginária) que só é possível à custa do esquecimento da totalidade da tradição que está na origem". Segundo a autora, esse esquecimento "não significa que a tradição deixe de determinar o sujeito". Ao contrário, e concordando com o pensamento de Hannah Arendt, ela alega que a tradição se torna ainda mais poderosa na medida em que o sujeito vive sem saber o que o domina. 47

\section{DEVIR-MULHER E O RESGATE DA SUBJETIVIDADE COMO FORMA DE PRODUÇÃO DE SENTIDO}

Nas sociedades ocidentais contemporâneas, surge uma nova figura social do feminino, representando um grande avanço democrático em relação ao status social e identitário, rompendo assim, com a ordem social naturalizada e preordenada.

\footnotetext{
45 ROSANVALLON, Pierre. La legitimidade democrática- Imparcialidad, reflexividad y proximidad. Madrid: Espasa Libros, S.L.U., 2010. p. 244.

46 ROSANVALLON, Pierre. La legitimidade democrática- Imparcialidad, reflexividad y proximidad. Madrid: Espasa Libros, S.L.U., 2010, p. 251-252.

$47 \mathrm{KEHL}$, Maria Rita. Deslocamentos do feminino: A mulher freudiana na passagem para a modernidade. Rio de Janeiro: Imago Ed., 1998, p. 40.
} 
BERTASO, João Martins; BERTASO, Candice Nunes. Aspectos da subjetividade na questão de gênero em Luis Alberto Warat. Revista Eletrônica Direito e Política, Programa de Pós-Graduação Stricto Sensu em Ciência Jurídica da UNIVALI, Itajaí, v.15, n.3, 3ㅇ quadrimestre de 2020 . Disponível em: www.univali.br/direitoepolitica - ISSN 1980-7791

Kehl alega que ao recuperar a tradição no sentido de entender esses lugares sociais impostos tanto para o homem, quanto para a mulher,

[...] não tem absolutamente o sentido de propor que nos reinstalemos nela - o que seria no mínimo farsesco, dado os tremendos deslocamentos que a cultura ocidental sofreu neste último século. Tem, sim, o sentido de dar voz ao que foi recalcado, e com isto evitar justamente a repetição característica dos efeitos do inconsciente. Conhecer as origens do discurso que confere às mulheres um lugar fixado pela tradição - no campo do Outro é a primeira condição para que se possa pensar sobre ele, perceber o quanto pode ser modificado ou, mais ainda, o quanto já se modificou. ${ }^{48}$

A autora explica que quando se trata do assunto de recuperar a produção histórica das tradições que nos constitui, há dois séculos, o que hoje a psicanálise entende como "posição feminina", como também, o modo pelo qual esta posição foi associada às mulheres, não é para propor que esta tradição possa revelar o "verdadeiro" ser da mulher. Ao contrário: ao desnaturalizar aquilo que foi construído pela cultura, espera-se que se criem possibilidades para que as mulheres possam constituir como lhes convier a relação com a feminilidade. 49

Isso é o que se chama para Warat de "devir-mulher", neste devir "não existe nenhuma busca de essências, nenhum ajuste à uma normatividade ideal", ou seja, "não há lei do gênero para a mulher", o que existem são "devires". 50

Entende que, o que existe é um reconhecimento do devir mulher como única condição, ou seja,

\footnotetext{
$48 \mathrm{KEHL}$, Maria Rita. Deslocamentos do feminino: A mulher freudiana na passagem para a modernidade. Rio de Janeiro: Imago Ed., 1998. p. 45.

$49 \mathrm{KEHL}$, Maria Rita. Deslocamentos do feminino: A mulher freudiana na passagem para a modernidade. Rio de Janeiro: Imago Ed., 1998, p. 45. Segundo a autora, "o esquecimento da dimensão simbólica que nos determina tende a criar um sentido de permanente "naturalização" (imaginária) quanto às instituições, conceitos e discursos que presidem nossa vida".
}

50 WARAT, Luis Alberto. Por quem cantam as sereias / Luiz Alberto Warat; trad. Por Julieta Rodrigues Sabóia Cordeiro. Porto Alegre: Síntese, 2000, p. 135. 
BERTASO, João Martins; BERTASO, Candice Nunes. Aspectos da subjetividade na questão de gênero em Luis Alberto Warat. Revista Eletrônica Direito e Política, Programa de Pós-Graduação Stricto Sensu em Ciência Jurídica da UNIVALI, Itajaí, v.15, n.3, 3ㅇ quadrimestre de 2020 . Disponível em: www.univali.br/direitoepolitica - ISSN 1980-7791

Não há sujeito-mulher, o que há são agenciamentos coletivos de enunciação; não há especificidade feminina, o que há são linhas vivas, linhas quebradas. Devir-mulher, é voltar-se cada vez mais sóbria, mais simples, cada vez mais deserta e, por essa mesma razão, povoada. O passeio que se desfruta, como ato, como política, como experimentação da vida, como criatividade. O uso nômade da vida. Sempre a busca de um mais além do desejo como o mais refinado gesto de criatividade. Fazer do pensamento uma força nômade que a libere das normas convertidas em modelo e arma de dominação. ${ }^{51}$

Em relação à ordem que condiciona a subjetividade feminina e masculina e seus lugares sociais, Warat ensina que "a categoria do gênero, pode ocupar-se da subjetividade masculina e seus mal-estares", porém, "tem sido pouco empregada nesse sentido". No entanto,

É uma categoria que geralmente vem sendo utilizada para enriquecer a compreensão da subjetividade feminina culturalmente vulnerável e o mal-estar das mulheres diante dos modos em que se encontram afetadas no exercício de seus diversos lugares sociais. [...] Por exemplo, existem poucos estudos sobre os ideais culturais que normatizam rigidamente o sentimento de ser dos homens, o que devem fazer e desejar para serem reconhecidos como tais e diferenciados das mulheres. Estou fazendo referência a ordem cultural que condiciona e/ou determina o narcisismo masculino, suas buscas de amor e reconhecimento (diante de si mesmo e ante os demais). O formato da masculinidade determinado pela cultura. A lei do gênero, os mandatos primários desde que o homem (ou a mulher) constrói seu sentimento de si. [...] A lei do gênero faz referência às tipificações (e/ou estereotipações) que normatizam formas diferentes de subjetividade, conforme o sexo que se possua. É uma lei que organiza de um modo maniqueísta as condições existenciais de ambos os sexos, assim como regula os comportamentos socialmente requeridos para ser hetero e auto reconhecido como homem ou mulher. Uma lei

51 WARAT, Luis Alberto. Por quem cantam as sereias / Luiz Alberto Warat; trad. Por Julieta Rodrigues Sabóia Cordeiro. Porto Alegre: Síntese, 2000, p. 135-136. 
BERTASO, João Martins; BERTASO, Candice Nunes. Aspectos da subjetividade na questão de gênero em Luis Alberto Warat. Revista Eletrônica Direito e Política, Programa de Pós-Graduação Stricto Sensu em Ciência Jurídica da UNIVALI, Itajaí, v.15, n.3, 3ㅇ quadrimestre de 2020 . Disponível em: www.univali.br/direitoepolitica - ISSN 1980-7791

que, naturalizando as diferenças, nega a produção social da subjetividade. 52

Warat fala que a lei do gênero, foi pouco tematizada com os homens, e que ela determina de um modo silencioso, quais atributos de masculinidade que se assegura para os machos de nossa espécie, e o ideal de masculinidade no âmbito políticos e sobre os outros. E diz que a autossatisfação irá aumentando na medida em que cada indivíduo se aproxime mais destes requisitos ideais, acarretando em altos preços sociais e psicológicos pagos por tal inadequação. 53

O gênero promove a realização do desejo e da sexualidade, ensejando processos de autonomia e de uma fundamental transformação na vida individual e social das pessoas. É um estilo de vida que possibilita encontrar o seu sentido, ou seja, é "o modo pelo qual organizamos o devir do desejo da realidade como sentido". 54

Liberar os sentimentos reprimidos permite a transformação do indivíduo. É nesse ponto que Warat destaca a importância da questão de gênero. "O gênero é um devir", diz o autor, é também "um arroio de subjetividade que passa entre o masculino e o feminino normatizado, para permitir que ambos os sexos possam deixar-se surpreender pela vida". ${ }^{55}$ Assim,

$[\ldots]$, as mulheres estão mais próximas que os homens do gênero como devir. Os homens não conseguiram fissurar o tipo normativo que lhes exige exceder o tipo para ajustar-se ao mesmo. Pretendem fazer-se homens antes que devirhomens. O futuro da transformação social não deixa de ser uma aposta no encontro do homem e da mulher em seus

\footnotetext{
52 WARAT, Luis Alberto. Por quem cantam as sereias / Luiz Alberto Warat; trad. Por Julieta Rodrigues Sabóia Cordeiro. Porto Alegre: Síntese, 2000, p. 134.

53 WARAT, Luis Alberto. Por quem cantam as sereias / Luiz Alberto Warat; trad. Por Julieta Rodrigues Sabóia Cordeiro. Porto Alegre: Síntese, 2000, p. 134.

54 WARAT, Luis Alberto. Territórios Desconhecidos: A Procura Surrealista pelos Lugares do Abandono do Sentido e da Reconstrução da Subjetividade. Vol 1. Florianópolis: Fundação Boiteux, 2004, p. 411.

55 WARAT, Luis Alberto. Por quem cantam as sereias / Luiz Alberto Warat; trad. Por Julieta Rodrigues Sabóia Cordeiro. Porto Alegre: Síntese, 2000, p. 136.
} 

Alberto Warat. Revista Eletrônica Direito e Política, Programa de Pós-Graduação Stricto Sensu em Ciência Jurídica da UNIVALI, Itajaí, v.15, n.3, 3ㅇ quadrimestre de 2020 . Disponível em: www.univali.br/direitoepolitica - ISSN 1980-7791

próprios devires. O social transformando-se no entre nós destes devires. Cada devir roubando-lhe algo que the permita multiplicar sua própria condição de surpresa diante da vida. ${ }^{56}$

O autor explica que além da lei do gênero, o homem deverá passar por provas no espaço público para ser socialmente reconhecido no que se refere à sua masculinidade. Necessitam se adequar às normas postas por outros homens para que sua condição masculina não seja questionada. O elemento narcisista que aí reside, demonstra certa disposição de produção de sentido para a sua subjetividade, e consequentemente traz à tona sua identidade.

Warat se aprofunda nesta questão, explicando que os homens se perguntam se são suficientemente homens. E ainda que,

A hombridade sempre questionada, permanentemente à beira de sua desqualificação. Isto gera um imperativo que legitima o excesso de comportamento reiterado. [...] $\mathrm{O}$ excesso no lugar do ainda mais do desejo. O excesso de hombridade no lugar do devir dos desejos. Em qualquer crise de subjetividade sempre há um excesso que a nega. Trata-se provar que se é mais homem para ignorar qualquer tipo de frustração. O excesso assegurando uma imagem (valorizada em muitos casos de uma maneira maior que a própria vida). Com o que os homens não sabem cuidar de si nem amar. Perdem a liberdade em nome de um ideal excedido em hombridade. ${ }^{57}$

Tais reflexões de Warat vão ao encontro do pensamento de Gilles Lipovetsky, quando este fala sobre os ideais característicos de cada sexo e das normas de socialização estruturadoras de suas personalidades, de seus gostos e dos comportamentos de cada gênero. Segundo Lipovetsky, a educação e a preparação de meninos e meninas é diferente em relação ao poder e à posição social. Explica que

\footnotetext{
56 WARAT, Luis Alberto. Por quem cantam as sereias / Luiz Alberto Warat; trad. Por Julieta Rodrigues Sabóia Cordeiro. Porto Alegre: Síntese, 2000, p. 136-137.

57 WARAT, Luis Alberto. Por quem cantam as sereias / Luiz Alberto Warat; trad. Por Julieta Rodrigues Sabóia Cordeiro. Porto Alegre: Síntese, 2000, p. 134-135.
} 

Jurídica da UNIVALI, Itajaí, v.15, n.3, 3ㅇ quadrimestre de 2020 . Disponível em: www.univali.br/direitoepolitica - ISSN 1980-7791

La ventaja masculina podría ser doble. Mientras que los hombres se hallan sumidos em uma cultura más competitiva, que desarrolla las pretensiones, la confianza y la sobreestimação de sí, necessárias para el ejercicio del liderazgo, las mujeres, por su parte, se vem 'impedidas' por uma socialización sobreprotectora que entraña una autoestima menos desarrollada. ${ }^{58}$

Estas normas sociais e identitárias estabelecem vantagens ao homem no momento em que ele galga os degraus hierárquicos da vida profissional, pois orientam preferencialmente os homens em direção à competição e aos resultados, já a mulher, ao plano relacional e íntimo. O poder imaginário competitivo concernente ao homem traz a ele a ânsia pela dominação, à valorização de sua virilidade e força física.

A identidade masculina consente aos homens a garantia de sua hegemonia nas instâncias de poder. Quando as mulheres alcançam os postos decisórios, especificamente, postos de alta gestão, poucas chegam ao nível máximo, ficando nas posições hierarquicamente inferiores do mundo das empresas ou dos governos.

A mulher sempre se encontrou subordinada ao homem, ele pensava por ela e a definia como ele queria que ela fosse. A mulher seguia regras petrificadas estabelecidas pela comunidade social como se fossem de sua própria natureza. Entretanto, Lipovetsky argumenta que nos tempos atuais, surge um novo modelo que ordena o lugar e o destino da mulher na sua vida social.

Nuevo modelo que se caracteriza por su autonomización en relación con la influencia que tradicionalmente han ejercido los hombres sobre las definiciones y significaciones imaginário-sociales de la mujer. ${ }^{59}$

Um novo modelo feminino mudou-se para o cenário do mundo ocidental, há mais ou menos três décadas, conquistando o poder de dispor de si mesma, de

\footnotetext{
58 LIPOVETSKY, Gilles. La tercera mujer. Barcelona: Editorial ANAGRAMA, S.A., 1999. p. 279.

59 LIPOVETSKY, Gilles. La tercera mujer. Barcelona: Editorial ANAGRAMA, S.A., 1999, p. 218.
} 
BERTASO, João Martins; BERTASO, Candice Nunes. Aspectos da subjetividade na questão de gênero em Luis Alberto Warat. Revista Eletrônica Direito e Política, Programa de Pós-Graduação Stricto Sensu em Ciência Jurídica da UNIVALI, Itajaí, v.15, n.3, 3ㅇ quadrimestre de 2020 . Disponível em: www.univali.br/direitoepolitica - ISSN 1980-7791

decidir sobre seu corpo e sua fertilidade, do direito ao conhecimento e de realizar qualquer atividade. Entretanto, diz Lipovetsky, que esta mudança não significa uma mutação histórica absoluta que faz uma limpeza do passado.

O autor ao analisar o livro "O Segundo Sexo" (1949), constata que a maneira como Simone de Beauvoir definiu o ser feminino por sua subordinação ao homem, não descreve mais a nova condição das mulheres. Após os anos 60 e as transformações sociais e culturais que ocorreram no Ocidente, houve o advento histórico da mulher-sujeito, uma mulher moderna dos anos 90, o que Lipovetsky chama de: A Terceira Mulher. 60

Essa lógica de dependência segundo Lipovetsky, não normatiza mais a condição feminina nas democracias ocidentais. "[...] el destino femenino entra por primera vez en una era de imprevisibilidade y de apertura estructural". 61 Dialogando com Warat, é a surreal imprevisibilidade que este, dizia ser a questão de possibilidade de autonomia do indivíduo. A tão sonhada autonomia feminina que a possibilita redefinir, reinventar, dirigir e criar a sua própria vida como ela bem quiser.

Lipovetsky segue demonstrando que a

Desvitalización del ideal de la mujer de su casa, legitimidad de los estúdios y el trabajo femininos, derecho de sufrágio, 'descasamiento', libertad sexual, control sobre la

\footnotetext{
60 A expressão "A terceira mulher" diz respeito ao fato de o autor ter estudado os diferentes momentos da condição feminina ao longo da história. Assim, distinguiu em três fases: a da primeira mulher, a da segunda mulher e por último da terceira mulher tratada no artigo. Durante o período mais longo da história da humanidade, as mulheres eram consideradas um mal necessário, um ser inferior, sistematicamente desprezado pelos homens, restrita às atividades sem brilho e notoriedade. Essa é a que Lipovetsky denomina de "a primeira mulher". Uma mudança cultural e histórica muito importante começou a ocorrer após a segunda Idade Média, baseada no código do amor cortês que adorava a amada dama e exacerbava suas perfeições morais e estéticas. Diferentemente do que ocorria no passado, os atributos característicos da mulher, são venerados entre os séculos XVIII e XIX. Saindo da figura maldita da mulher, nesse momento a mulher é então, exaltada. É esposa, mãe e educadora de crianças que são colocadas em um pedestal por filósofos, ideólogos e poetas. Conforme a análise de Lipovetsky, esta é a chamada "segunda mulher". Porém ainda não era reconhecida como sujeito igual e autônomo, seus prestígio social era devido ao seu pai e a seu marido, mas seus papéis se tornam socialmente reconhecidos e celebrados. Foi destacado o poder de educar as crianças, para educar homens e comportamentos incivilizados.
}

${ }^{61}$ LIPOVETSKY, Gilles. La tercera mujer. Barcelona: Editorial ANAGRAMA, S.A., 1999, p. 218. 

Jurídica da UNIVALI, Itajaí, v.15, n.3, 3ㅇ quadrimestre de 2020 . Disponível em: www.univali.br/direitoepolitica - ISSN 1980-7791

procreación son otras tantas manifestaciones del acceso de las mujeres a la completa disposición de sí mismas em todas esferas de la existência, $[\ldots] .62$

É correto dizer segundo o autor, que hoje é reconhecido às mulheres e aos homens o direito de gerir o seu próprio destino, mas não significa que isso tenha provocado uma troca de seus lugares. Apesar dos grandes avanços que as mulheres obtiveram neste último meio século, Lipovetsky argumenta que a dinâmica democrática ainda não atingiu de todo os seus fins.

El hombre sigue asociado prioritariamente a roles públicos e «instrumentales», la mujer a roles privados, estéticos y afectivos; lejos de obrar una ruptura radical con el pasado histórico, la modernidad labora por reciclarlo sin cesar. La época de la mujer sujeto conjuga discontinuidad y continuidad, de-terminismo e impredictibilidad, igualdad y diferencia; la tercera mujer ha conseguido reconciliar a la mujer radicalmente nueva y a la mujer siempre repetida. ${ }^{63}$

Dessa forma, é demonstrado que nas vidas individuais há uma confluência de descontinuidade e continuidade, de determinismo e imprevisibilidade, de igualdade e diferença. Para Lipovetsky esse conflito que se opõe a busca da igualdade e da lógica social da alteridade dos sexos, soluciona-se no fato de que ambos triunfam em conformidade, em vez de prevalecerem um sobre o outro. Assim, na modernidade democrática, as diferentes posições de gênero que atualmente são mais sustentadas, não significam mais um obstáculo ao princípio da livre autodisposição.

Assim, a mudança de comportamento em relação ao trabalho e à família, não mudou a indeterminação dos papéis sociais. A questão é a de que

La novedad no reside en el advenimiento de un universo unisex, sino en una sociedad abierta en que las normas, al ser plurales y selectivas, se acompañam de estrategias heterogèneas, de márgenes de latitud y de indeterminación. Allí donde las determinaciones eran mecanicistas, hay

62 LIPOVETSKY, Gilles. La tercera mujer. Barcelona: Editorial ANAGRAMA, S.A., 1999, p. 218.

63 LIPOVETSKY, Gilles. La tercera mujer. Barcelona: Editorial ANAGRAMA, S.A., 1999, p. 12. 

Jurídica da UNIVALI, Itajaí, v.15, n.3, 3ㅇ quadrimestre de 2020 . Disponível em: www.univali.br/direitoepolitica - ISSN 1980-7791

cabida en la actualidad para opciones y arbitrajes individuales. 64

Warat também nos fala que os modelos sociais atribuíam papéis e lugares coercitivamente aos indivíduos, mas hoje de acordo com Lipovetsky, eles apenas orientam e indicam preferências estatísticas. Os papéis exclusivos deram lugar à liberdade de escolha, de governar a si mesmo e à abertura de oportunidades, sendo aplicado a ambos os sexos. Por fim, Lipovetsky declara que não é a igualdade dos papéis sexuais que prevalece, "sino la no regência de los modelos sociales y, correlativamente, la potencia de autodeterminación y de indeterminación subjetiva de los dos géneros. 65

Warat propõe o cuidado com a vida e a subjetividade como forma de resgatar o sentido dela e o valor do outro, através dos afetos. Percebe-se que homens e mulheres contemporâneos procuram dar ênfase à solidariedade, à fraternidade, à ajuda mútua, aos laços afetivos e ao amor. Amor em todas as suas dimensões, sendo o solvente universal para todos os males. Alega que na história muito se falou sobre o amor, mas pouco se viveu o amor.

O desafio do ser humano é se relacionar com o outro de uma forma construtiva e amorosa, sem machucar, sem causar sofrimento. O ensinamento que fica de Luis Alberto Warat é que o amor não é obrigatório. Não se pode ensinar que a pessoa aprenda a ser sensível, mas tem que ajudar a aprender a amar. Ajudar as pessoas a serem sensíveis, é ajudar a descobrir em si a própria sensibilidade. Em suma, os relacionamentos humanos são aprendizados para se viver com a aceitação, com o perdão e como lidar com as frustações, com a tristeza, com a raiva, com a possessividade, com o ódio e com a intolerância.

64 LIPOVETSKY, Gilles. La tercera mujer. Barcelona: Editorial ANAGRAMA, S.A., 1999, p. 220.

65 LIPOVETSKY, Gilles. La tercera mujer. Barcelona: Editorial ANAGRAMA, S.A., 1999, p. 221. 

Jurídica da UNIVALI, Itajaí, v.15, n.3, 3ㅇ quadrimestre de 2020 . Disponível em: www.univali.br/direitoepolitica - ISSN 1980-7791

\section{CONSIDERAÇÕES FINAIS}

Encaminham-se algumas considerações na certeza de que não se esgotou a temática e nem os referenciais teóricos aqui trabalhados.

A questão problema que norteou o desenvolvimento do presente texto, instigou a estabelecer uma conexão epistemológica entre igualdade, diferença, reconhecimento, identidade e autonomia como possibilidade de resgate da subjetividade masculina e feminina.

Um primeiro aspecto constatado, remete à (re)construção dos gêneros no sentido democrático, qual seja, a liberdade de autodeterminação e de gestão das pessoas. Esse avanço democrático aplicado ao status social e identitário feminino ensejou uma quebra de paradigma dos modelos sociais instituídos e a desconexão do espaço do poder público do privado.

O século $\mathrm{XX}$ foi o grande momento das mulheres, onde através dos movimentos sociais e de lutas por reconhecimento houve a transformação da condição feminina e uma revolução no seu destino e na sua identidade nas ultimas três décadas. Nas sociedades ocidentais contemporâneas, surge um novo modelo que se caracteriza pela sua autonomia em relação à influência tradicionalmente exercida pelos homens sobre as definições e significados imaginário-sociais das mulheres.

Antes, escravas da procriação, com sonhos de realização pessoal ligado unicamente a ser mães e donas de casa, submetidas em sua expressão sexual por uma moralidade severa, as mulheres agora afirmaram novas formas de estar no mundo onde transcendem o que eram imposições/mandamentos tradicionais e naturalizados.

Também, constata-se que esse novo modelo que vai se consolidando, e dando autonomia das mulheres, repercute sobre o descrédito dos comportamentos machistas e a incursão das mulheres no mercado de trabalho, favorece a 

Jurídica da UNIVALI, Itajaí, v.15, n.3, 3ㅇ quadrimestre de 2020 . Disponível em: www.univali.br/direitoepolitica - ISSN 1980-7791

participação igualitária de tratamento de ambos os gêneros. Uma sociedade mais igualitária e participativa se vislumbra como um referencial cultural de paz.

Percebe-se que por mais que a mulher tenha passado por um significativo processo de transformação, ainda mantém alguns comportamentos tradicionais simultaneamente com os novos. Aceita papéis tradicionais, mas não sacrifica o trabalho pela família, cobra para ser uma nova mulher, mas conserva algumas características da primeira e segunda mulher de Lipovetsky, ou seja, a terceira mulher concilia a mulher radicalmente nova e a mulher sempre repetida.

É possível ver que a questão do gênero não é mais vista somente como um dos fatores da subjetividade masculino-feminina, ou seja, não tem apenas um caráter único e universal. Almeja-se apontar um olhar diferente sobre os devires da subjetividade humana. O destino feminino embarca em uma era de imprevisibilidade, de abertura estrutural, do incerto, do novo, do indefinido. Imprevisibilidade essa que possibilita sua autonomia, de reinventar e criar sua vida como ela necessitar e dispuser de condições.

Um aspecto relevante se verifica na proposta Waratiana, a de que não há lei do gênero para a mulher, o que existe é um reconhecimento do devir mulher como única condição de sentido para a vida, é o modo pelo qual constituímos o devir do desejo da realidade como sentido. Assim, entendida através desse olhar, é nesse ponto que se destaca a importância da questão de gênero. 0 gênero como um devir, como uma vertente de subjetividade que passa entre o masculino e o feminino normatizado, para permitir que ambos os sexos possam deixar-se surpreender pela vida.

Assim diante da questão proposta, é possível vincular o pensamento Waratiano com Lipovetsky, acenando que o gênero como devir é a liberdade da mulher e do homem de se construir a partir de papéis diferentes. No que diz respeito à condição feminina, pode-se pensar que o futuro the pertence. 

Jurídica da UNIVALI, Itajaí, v.15, n.3, 3ㅇ quadrimestre de 2020 . Disponível em: www.univali.br/direitoepolitica - ISSN 1980-7791

\section{REFERÊNCIAS DAS FONTES CITADAS}

CASTELLS, Manuel. O Poder da Identidade. A Era da Informação: Economia, Sociedade e Cultura. Vol. 2. São Paulo: Editora Paz e Terra, 1999.

COSTA, Sérgio. Complexidade, diversidade e democracia. In Souza, Jessé (org). Democracia hoje: novos desafios para a teoria democrática contemporânea. Brasília: editora Universidade de Brasília, 2001.

DIAS, Maria Berenice. A lei Maria da Penha na justiça: a efetividade da lei 11.340/2006 de combate à violência doméstica e familiar contra a mulher. São Paulo: Editora Revista dos Tribunais, 2007.

, Maria Berenice. Aspectos jurídicos do gênero feminino. Construções e perspectivas em gênero. Organizado por Marlene Neves Strey; Flora Mattos; Gilda Fensterseifer e Graziela Werba. São Leopoldo: Ed. UNISINOS, 2000.

EISLER, Riane. O cálice e a espada - Nossa história, nosso futuro. Rio de Janeiro: Imago Ed, 1989.

FRASER, Nancy. Redistribuição, reconhecimento e diferença: por uma concepção integrada de justiça. In: IKAWA, Daniela; PIOVESAN, Flávia, SARMENTO, Daniel (org.). Igualdade, diferença e direitos humanos. Rio de Janeiro: Lumen Juris, 2008.

FOUCAULT, Michel. A história da sexualidade. Rio de Janeiro: Graal, 1988.

GOHN, Maria da Glória. Novas Teorias dos Movimentos Sociais. 3d. São Paulo: Edições Loyola, 2010.

HABERMAS, Jurgen. A inclusão do outro. São Paulo: Loyola, 2002.

HONNETH, Axel. Luta por reconhecimento: a gramática moral dos conflitos sociais. São Paulo: Ed. 34, 2003. 

Jurídica da UNIVALI, Itajaí, v.15, n.3, 3ㅇ quadrimestre de 2020 . Disponível em: www.univali.br/direitoepolitica - ISSN 1980-7791

KEHL, Maria Rita. Deslocamentos do feminino: A mulher freudiana na passagem para a modernidade. Rio de Janeiro: Imago Ed., 1998.

LIPOVETSKY, Gilles. La tercera mujer. Barcelona: Editorial ANAGRAMA, S.A., 1999.

NOBRE, Marcos. Luta por reconhecimento: Axel Honneth e a teoria crítica. In: HONNETH, Axel. Luta por reconhecimento: a gramática moral 'dos conflitos sociais. São Paulo: Ed. 34, 2003, p. 18.

PERROT, Michelle. Mulheres públicas. São Paulo: Fundação Editora da UNESP, 1998.

ROSANVALLON, Pierre. La legitimidade democrática- Imparcialidad, reflexividad y proximidad. Madrid: Espasa Libros, S.L.U., 2010.

TAYLOR, Charles. El multiculturalismo y "la política del reconocimiento". Tradução Mónica Utrilla de Neira. México: Fondo de Cultura Ecónomica, 2006. , Charles. Argumentos Filosóficos. São Paulo: Edições Loyola, 2000.

Charles. Multiculturalismo: Examinando a política de reconhecimento. Lisboa: Instituto PIAGET, 1994.

Alain. Um novo paradigma: para compreender o mundo de hoje / Alain Touraine; tradução de Gentil Avelino Titton. Petrópolis, RJ: Vozes, 2006.

Alain. O mundo das mulheres. Petrópolis, RJ: Vozes, 2007.

WARAT, Luis Alberto. Por quem cantam as sereias / Luiz Alberto Warat; trad. Por Julieta Rodrigues Sabóia Cordeiro. Porto Alegre: Síntese, 2000.

, Luis Alberto. Territórios Desconhecidos: A Procura Surrealista pelos Lugares do Abandono do Sentido e da Reconstrução da Subjetividade. Vol 1. Florianópolis: Fundação Boiteux, 2004. 
BERTASO, João Martins; BERTASO, Candice Nunes. Aspectos da subjetividade na questão de gênero em Luis Alberto Warat. Revista Eletrônica Direito e Política, Programa de Pós-Graduação Stricto Sensu em Ciência Jurídica da UNIVALI, Itajaí, v.15, n.3, 3ㅇ quadrimestre de 2020 . Disponível em: www.univali.br/direitoepolitica - ISSN 1980-7791

, Luis Alberto. A Ciência Jurídica e seus dos maridos. 2. Ed. Santa Cruz do Sul: EDUNISC, 2000.

, Luis Alberto. Manifestos para uma ecologia do desejo. São Paulo: Editora Acadêmica. 1990. 